\title{
A FECUNDIDADE DA \\ ECOLOGIA COSMOCENA NA \\ PERSPECTIVA DO CURRICULO E DA DIGNIDADE HUMANA
}

\author{
THE FERTILITY OF COSMOCENE ECOLOGY IN THE PERSPECTIVE \\ OF CURRICULUM AND HUMAN DIGNITY
}

LA FECUNDIDAD DE LA ECOLOGÍA COSMOCENA EN LA
PERSPECTIVA DEL CURRICULO Y LA DIGNIDAD HUMANA

Vilmar Pereira

http://orcid.org/oooo-0oo3-2548-5086

Simone Grohs Freire

(i) http://orcid.org/oooo-0oo3-3566-0669

Márcia Pereira da Silva

D http://orcid.org/ooo-0oo2-6249-6625

\author{
REVISTA PEDAGÓGICA \\ Revista do Programa de Pós-graduação em Educação da Unochapecó | ISSN 1984-1566 \\ Universidade Comunitária da Região de Chapecó | Chapecó-SC, Brasil \\ Como referenciar este artigo: PEREIRA, V.; FREIRE, S. G.; SILVA, M. P. A fecundidade da ecologia cosmocena \\ na perspectiva do curriculo e da dignidade humana. Revista Pedagógica, Chapecó, v. 21, p. 462-48o, 2019.
} DOI: http://dx.doi.org/10.22196/rp.v22io.5141

RESUMO: O estudo aqui apresentado propõe pensar o currículo e a dignidade humana com base nas teses apresentadas pela Ecologia Cosmocena, acenando para uma nova compreensão da relação humanidadenatureza, reconhecendo que a era Antropocena, em que se avaliam os impactos das atividades humanas como sendo determinantes na alteração ecológica do Planeta, já não consegue responder às necessidades deste tempo de crise. A reflexão sobre um currículo pautado nestas teses sugere um convite hermenêutico de reposicionarmos ações e escolhas que possam estabelecer outras relações humanidade-natureza. Mobiliza a refletir sobre a necessidade de ressignificar o princípio da dignidade a partir de uma compreensão do mundo que se habita para que os sentidos da existência humana sejam renovados em um olhar compassivo pelo outro. Sobretudo convida a superação das dicotomias, injustiças e barreiras desumanizantes que, cunhadas por um capitalismo sem limites aumenta incertezas, descrenças e desumanidades.

Palavras-chave: Ecologia Cosmocena. Educação. Dignidade humana. Curriculum. Ser.

ABSTRACT: The study presented here proposes to think the curriculum and the human dignity based on the thesis presented by Cosmocene Ecology, waving to a new understanding of the humanity-nature relation, recognizing that the Anthropocene era, in which the impacts of human activities are evaluated as being determinants in the ecological change of the Planet, can no longer respond to the needs of this time of crisis. The thinking on a curriculum based on these theses suggests a hermeneutic invite to reposition actions and choices that may establish other human-nature relations. It mobilizes to reflect about the need to resignify the principle of dignity from an understanding of the world that is inhabited so that the senses of the human existence are renewed in a compassionate view of the other. Above all, it invites to the overcoming of dichotomies, injustices and dehumanizing barriers that, coined by a limitless capitalism increases uncertainties, disbelief and inhumanities.

Keywords: Cosmocene Ecology. Education. Human dignity. Curriculum. Being.

RESUMEN: El estúdio aquí presentado propone pensar el currículo y la dignidad humana con base en las tesis presentadas por la Ecología Cosmocena, acentuando para una nueva comprensión de la relación humanidadnaturaleza, reconociendo que la era Antropocena, en que se evalúa los impactos de las actividades humanas como determinantes en la alteración ecológica del Planeta, ya no puede responder a las necesidades de este tiempo de crisis. La reflexión sobre un currículo pautado en estas tesis sugiere una invitación hermenéutica de reposicionar acciones y elecciones que puedan establecer otras relaciones humanidad-naturaleza. Moviliza a reflexionar sobre la necesidad de resignificar el principio de la dignidad a partir de una comprensión del mundo que se habita para que los sentidos de la existencia humana sean renovados en una mirada compasiva por el otro. Sobre todo invita a la superación de las dicotomías, injusticias y barreras deshumanizantes que, acuñadas por un capitalismo sin límites aumenta incertidumbres, incredulidad e inhumanidad.

Palabras clave: Ecología Cosmocena. La educación. Dignidad humana. Plan de estudios. Sea. 


\section{Introdução}

Em estudo anterior sobre Ecologia Cosmocena (PEREIRA, 2016), partiu-se do contexto já evidenciado das múltiplas crises: civilizatória (LEFF, 2006), crise de sentido (ZOHAR; MARSHALL, 2012), crise entre ciência e religião (WILSON, 2008) e, por decorrência, crise socioambiental (LOVELOCK, 2010; BOFF, 2012; LOUREIRO, 2004) e a crise de paradigma, em que o paradigma metafísico, este que se acreditou ser portador de sentido na busca dos fins últimos da humanidade. Associado a isso, emerge muito forte da ideia da era Antropocena que foi oficialmente lançada pelo vencedor do Prêmio Nobel Paul Crutzen, em 2002, na revista Nature. Nesse sentido, os cientistas quando assumem essa terminologia, admitem que ela é resultado dos visíveis níveis de intervenção do humano no cosmos, em especial na Terra. "Estou falando sobre sinais que marcam claramente a era Antropocena como um intervalo separado no tempo geológico. Assim, precisamos mostrar que o termo é geologicamente justificável" (ZALASIEWICZ, 2011).

Em nossa compreensão, há dois movimentos sobre o entendimento da referida era. Um primeiro que considera que sim, já estamos nela. Um segundo, mais cauteloso, que ainda avalia para um emitir um resultado mais conclusivo em termos de reconhecimento.

Aqueles primeiros que vêm estudando essa temática, ao considerarem que estamos passando da era Holocena para a Antropocena, reconhecem três grandes períodos na história da Antropocena (VALE; CAIXETA, 2011): 1. Formação da Era Industrial de 1800 a 1945; 2. A grande aceleração de 1945 a 2000 (que ainda continua); 3. O Antropoceno 3.0, em que o movimento desperta para a consciência de si mesmo que emerge mediante a chamada modernidade reflexiva e dos dilemas da sustentabilidade. É consenso entre eles que estamos em um período de perdas irreversíveis e com mudanças catastróficas, deixando visíveis, cada vez mais, os sinais de mudanças globais que estão alterando tanto a conjuntura biofísica e socioeconômica quanto as dimensões estruturais no que diz respeito ao funcionamento da Terra como um sistema.

Quanto ao segundo grupo, cujos integrantes são arqueólogos, geoquímicos, oceanógrafos e paleantólogos, após reunião realizada em 2016 na Noruega, decidiram adiar para 2018 a oficialização sobre o início do processo de reconhecimento de que a terra já se encontra na era Antropocena. Essa informação é da pesquisadora Juliana Assunção Ivar do Sul, da Universidade Federal do Rio Grande (FURG), Brasil, integrante do grupo. Mesmo reconhecendo inúmeros indícios e transformações nas camadas e rochas bem como na superfície do fundo mar pelo excesso abusivo de uso de plástico, demais fragmentos de materiais artificiais e as alterações que deles decorrem por não diluírem, Ivar do Sul (2016, p. 52) é cautelosa quando afirma: 
"[...] propor uma era geológica é algo muito complexo [...] precisamos de mais evidências científicas". Mesmo não havendo ainda consenso entre os dois grupos e percebendo a existência de aspectos políticos na referida época geológica, há algo em comum entre ambos: "As transformações ambientais provocadas pela ação humana são tão intensas que já produziram marcas indeléveis no registro geológico do planeta" (IVAR DO SUL, 2016, p. 52).

Estes são fortes elementos que contribuem para a emergência da concepção de Ecologia Cosmocena. Desse modo, o estudo procurou, a partir de oito teses, discutir e problematizar: a) relação Natureza-Humanidade reivindicando uma postura de maior reconhecimento das outridades que integram a natureza desde já, e que por decorrência também são sujeitos. Para, além disso, sugere uma postura de maior humildade superando essa pretensa relação de domínio humanidade-natureza, onde, com maior sintonia, é possível o ser humano perceber-se como mais uma espécie nesse infinito universo. Abertura e redefinição de postura são os elementos orientadores dessa propositiva relação; b) Da desaceleração do tempo como garantia de vida emergem profundas e densas reflexões sobre a concepção de tempo e sobre como estamos compreendendo o tempo no horizonte pós-metafísico. Isso é posto, dado ao fato de que nos orientamos pela concepção moderna de tempo. Apresenta-se como reflexão o conceito de presenteísmo e as possíveis anomalias de uma humanidade que reclama não ter tempo e que vive os tempos de aceleração e bloqueamento de todas as capacidades criativas. Reivindica-se tempo para nossos afetos, nossas estéticas, éticas e místicas. Inclusive tempo para desacelerar; c) Da sintonia com novas sabedorias: chama-se atenção para tantas sabedorias que sempre estiveram aí, mas que, em geral, não estabelecemos sintonias profundas com elas. Isso vai desde os saberes dos povos tradicionais aos múltiplos movimentos na luta pela vida que estão ocorrendo durante todo ano em todo o planeta. A reivindicação hermenêutica aqui é de maior abertura compreensiva; d) Do cuidado como reaprendizagem $x$ consumo desenfreado: partindo da constatação de que somos uma sociedade que se cuida pouco, o estudo aponta desde a gênese cuidado como condição ontológica do ser humano, passando por diferentes formas de descuido e sugere o cuidado como condição fundamental para sustentabilidade do universo. Apresenta também alguns movimentos na direção do cuidado e de uma cultura da paz; e) Da descolonização do mundo da vida: parte do conceito de Jürgen Habermas de colonização do mundo da vida e embasado em estudos de Zygmunt Bauman sobre o impacto que as redes sociais têm sobre a geração de consumidores - em especial, a obra "Vida Para Consumo" -, apresenta reflexões sobre a colonização de nossa dimensão das estruturas linguísticas, culturais, afetivas, subjetivas que sofrem esse grande impacto muitas vezes perdendo ou criando anomalias, inclusive na nossa capacidade de 
comunicação e nas dimensões de diálogos com aqueles (as) que estão próximos; f) Por um mundo diverso e sem preconceitos: com base na compreensão que o universo sempre foi biodiverso, plural e múltiplo, o estudo denúncia todas as formas de preconceito reconhecendo que todas encolhem a expressão da vida em múltiplos contextos. Denuncia também o preconceito epistemológico tão reforçado em muitas academias. Para, além disso, essa ecologia se manifesta como aberta a todas as diferenças transcendendo o estreitamento de fronteiras e reivindicando novos modos ser nesse infinito universo; g) Da condição de incompletude: o estudo parte da compreensão da nossa vocação ontológica que leitura freiriana aponta para essa condição de ser mais. E nesse horizonte do ser mais, discute e reconhece três vertentes polêmicas: a necessidade de uma nova aproximação entre ciência e religião (WILSON, 2008); o reconhecimento do coeficiente espiritual QS, não como religião, mas como uma espécie de bússola moral na busca de superação da nossa crise de sentido (ZOHAR; MARSHALL, 2012) e o reconhecimento da existência da alma. Esses aspectos pressupõem como ponto de partida o fato de que, mesmo não acreditando em nenhuma dimensão transcendental-espiritual, devemos reconhecer que para bilhões de seres humanos essa dimensão assume sentido profundo em suas vidas e modos de ser. h) Do lugar $d a$ Educação Ambiental na Ecologia Cosmocena: considera que a EA aparece um ponto pequeno nesse universo, mas que assume o papel preponderante no sentido de nos ressituar sobre os caminhos que traçamos. Essa ampla discussão não se encontra desconexa das intervenções políticas e principalmente econômicas. Economia essa que limita as formas de vida no planeta. Ela pode servir de alternativa para pensarmos um desenvolvimento mais amplo do ser humano do que apenas a estreiteza da lógica financeira: desenvolvimento cultural, intelectual, espiritual das pessoas em suas múltiplas dimensões que possa garantir a qualidade de vida digna. É o que Capra denomina de crescimento qualitativo. É desse cenário que emerge a definição da Ecologia Cosmocena como:

[...] uma alternativa viável para pensarmos as relações entre seres vivos e não vivos no sentido de podermos garantir melhor qualidade de vida no planeta e, quem sabe, no universo. Ela nasce em meio a este cenário de desesperança e medo reforçado pela Era Antropocena e pelas consequentes crises: dos fundamentos da EA, do paradigma filosófico metafísico, da racionalidade ocidental e do sujeito, do esgotamento do sistema capitalista, da lógica do lucro e consequentemente da crise financeira, crise política, socioambiental e, fundamentalmente, da crise de sentido existencial-ontológico sobre o espaço e sentido humano no cosmos. Emerge também de 
uma profunda intuição hermenêutica de que é necessário um reposicionamento humano no cosmos no amplo conjunto das relações que estabelecemos cotidianamente com o universo com o qual nos encontramos conectados. Dessa forma, pode ser vista como ecologia também de ampliação dos sentidos, com a pretensão de alargar a nossa visão cósmica. (PEREIRA, 2016, p. 45).

\section{Primeira decorrência: a Pedagogia Cosmocena}

Um primeiro esforço compreensivo que realizamos como decorrência da referida Ecologia foi a partir de uma Pedagogia; logo, salientamos que cada princípio educativo que aqui emerge consiste em uma decorrência de uma das oito teses que sustentam a Ecologia Cosmocena. Desse modo, em estudo anterior apresentamos os possíveis desdobramentos pedagógicos dessa teoria.

1) Da nova relação Natureza-Humanidade - Aprendizagem Humanista relacional.

2) Da desaceleração do tempo como garantia de vida - Aprendizagem como Processo de valorização da vida.

3) Da sintonia com novas sabedorias - Aprendizagem Hermenêutica dos Saberes não reconhecidos.

4) Do cuidado como reaprendizagem $x$ consumo desenfreado - Aprendizagem do cuidado.

5) Da descolonização do mundo da vida - Aprendizagem dos Saberes Primevos.

6) Por um mundo diverso e sem preconceitos - Aprendizagem com as Diferenças.

7) $\mathrm{Da}$ condição de incompletude - Aprendizagem Transcendental.

8) Do lugar da Educação Ambiental na Ecologia Cosmocena - Aprendizagem do Ambiente inteiro.

Outras decorrências emergiram a partir dessa reflexão inicial. Uma delas, com bastante significado, veio da possibilidade pensarmos tanto o currículo quanto o princípio da dignidade humana.

2.1 Currículo Cosmoceno: um olhar sobre a multiplicidade do ser

O currículo na ação é a última expressão de seu valor, pois, enfim, é na prática que todo projeto, toda ideia, toda intenção, se faz realidade de uma forma ou outra; se manifesta, adquire significado e valor, independentemente de declarações e propósitos de partida. Às vezes, também, à margem das intenções a prática reflete pressupostos e valores muito diversos. (GIMENO SACRISTÁN, 1998, p. 201). 
A discussão sobre currículo é necessária à medida que pretendemos entender a constituição do currículo em uma escola sustentável. Mas, o que é então o currículo? Compreendemos o movimento do currículo como algo que se constitui como algo inacabado, feito em constante movimento dialético. Pensamos que é neste movimento do ainda não terminado, da incompletude, da mudança de rumo que o currículo se efetiva.

Para iniciarmos esta discussão, vamos pensar em primeira instância no significado da palavra currículo. Etimologicamente, curriculum é uma expressão latina que significa pista ou circuito atlético - tinha ressonâncias similares com "ordem como sequência" e "ordem como estrutura" (HAMILTON, 1992, p. 10). Gimeno Sacristán (2000) frisa que o termo vem da palavra latina currere, referindo-se à carreira, a um percurso a ser atingido, o que nos remete a diferentes concepções.

Para Gesser e Ranghetti (2011), o termo currículo, desde sua concepção como campo de trabalho específico na área educacional, tem apresentado diversas definições, muitas vezes polissêmicas e controversas. Moreira e Macedo (2002) e Moreira, Candau e Moreira (2007, p. 17) contribuem com esta discussão, explicando que esse termo se associa a distintas concepções, as quais derivam dos diversos modos de como a educação é concebida historicamente, bem como das influências teóricas que a afetam e se fazem hegemônicas em um dado momento. Os autores também colocam que diferentes fatores socioeconômicos, políticos e culturais contribuem para que currículo venha a ser entendido como:

(a) os conteúdos a serem ensinados e aprendidos; (b) as experiências de aprendizagem escolares a serem vividas pelos alunos; (c) os planos pedagógicos elaborados por professores, escolas e sistemas educacionais; (d) os objetivos a serem alcançados por meio do processo de ensino; (e) os processos de avaliação que terminam por influir nos conteúdos e nos procedimentos selecionados nos diferentes graus da escolarização. (MOREIRA; CANDAU. MOREIRA, 2007, p. 18).

Podemos afirmar, então, que o currículo designa assim, todas as ações que permeiam os espaços de educação, e, portanto, não é possível pensar em um currículo que não considere todos os aspectos históricos e sociais que formam um povo, que constituem uma sociedade ou um grupo social onde uma escola se localiza. A reflexão dos autores nos remete também a importantes questões a serem consideradas: Como utilizar um currículo mínimo e padrão se os espaços educativos estão nas mais diferentes comunidades? Como este poderia atender cada peculiaridade social de um povo e de faixas etárias tão diferentes? 
Se o currículo permeia todas as ações, encontramos outra reflexão necessária que é pensar como fazer a conexão necessária entre a palavra currículo e sua vigência no âmbito prático? Para Gimeno Sacristán (2000, p. 16), “[...] currículo é o contexto da prática, ao mesmo tempo em que é contextualizado por ela". Assim, transportamo-nos novamente à "história das gaivotas", uma vez que voar é um exercício de significados onde a teoria de voo e a prática de voar estão incondicionalmente unidas, ou seja, não podemos dissociar as ações da escola de suas intencionalidades ao agir e pensar.

O currículo se configura no sentido de ser o "elemento nuclear de referência" (GIMENO SACRISTÁN, 2000, p. 19), por exemplo, quando capturamos uma "foto de voo" nós mesmos desejamos "voar pelo mundo" para explorar um determinado local, mesmo que virtualmente. É, por meio do panorama, da imagem distante ou aproximada, ou seja, do currículo, que a escola se apresenta como instituição e manifesta-se como um espaço educador, como é de fato. O currículo é, por assim dizer, a referência da realidade da escola em todos os níveis e modalidades em que atua, como expressa sua práxis na formação dos que nela e com ela participam.

A elaboração e prática do currículo se substancia e se concretiza à medida que são considerados valores e culturas, compartilha responsabilidades, preza por direitos e deveres e, sobretudo, preza pela união entre prática e teoria. Conceber o currículo desta forma significa permitir um movimento constante de reformulação.

Com este movimento constante, salienta Gimeno Sacristán (2000, p. 21), "o currículo modela-se dentro de um sistema escolar concreto [...]". E as teorias que possam dar conta desses processos, necessitam partir de uma abordagem crítica, no sentido dado pela Teoria Crítica. Esta se refere ao pensamento de um grupo de intelectuais marxistas não ortodoxos, alemães, que, a partir dos anos 1920, desenvolveram pesquisas e intervenções teóricas sobre problemas filosóficos, sociais, culturais, estéticos gerados pelo capitalismo tardio e influenciaram sobremaneira o pensamento ocidental particularmente dos anos 1940 aos anos 1970 do século passado. Esses pensadores constituem a chamada "Escola de Frankfurt".

A Teoria Crítica propõe uma discussão permanente da realidade como influência direta ou indireta na constituição das propostas escolares críticas e, por assim serem, são inovadoras tanto quanto desafiadoras do sistema atual, posto que valoriza os saberes e fazeres das comunidades de aprendizagens. Neste olhar crítico, o currículo é constituído de tensões, conflitos, concessões culturais, políticas, sociais que se embatem continuamente em um exercício interminável constituído de subjetividade, interioridade, como instrumento que afeta e é afetado pelo contexto histórico que o compõe. A esse respeito, acrescentam Gesser e Ranghetti (2011, p. 46): 
[...] os currículos são historicamente construídos e carregados de intencionalidades, valores, conteúdos, entre outras coisas. Isto pode ser observado pelas reformas educacionais curriculares promovidas em diferentes momentos históricos, as quais têm sido direcionadas de acordo com as necessidades econômicas, sociais, políticas, entre outros interesses, ou seja, pelos modos de produção de um sistema capitalista.

Currículo é, portanto, uma rede de trocas que constituem o processo que concebemos como sendo uma educação democrática e participativa, capaz de responder abertamente os desafios e embates dessa forma de conceber o currículo. Dentro dessa perspectiva crítica, o currículo tem a pretensão de analisar, conhecer e se apropriar dos fazeres e saberes de cada comunidade, de cada região, por esta razão compartilhamos que "ensinar exige risco, aceitação do novo e rejeição a qualquer tipo de discriminação" (FREIRE; SHOR, 2006, p. 36). A aceitação do "novo" passa pelas escolhas que se faz enquanto se caminha pela direção que se propõe enquanto se vive o projeto-processo. Nesse sentido, aceitar não assume uma passividade como $a$ priori o verbo propõe, mas se põe em movimento, rompe com as fragmentações e, de repente, encontra um ressignificado para o currículo por hora posto em nossas comunidades escolares.

Pensar juntos, rejeitar discriminações, propor práticas que se convergem com a autonomia e a democracia nos aproximam do colocado por Sacristán como currículo, ou seja, como uma "confluência de práticas" (GIMENO SACRISTÁN, 1998, p. 102), [desenvolvidas] "[...] através de múltiplos processos e na qual se entrecruzam diversos subsistemas ou práticas diferentes e, sendo uma prática, [todos os que participam dela são sujeitos], elementos ativos, e não objetos" (GIMENO SACRISTÁN, 1998, p. 165). O diálogo de ideias de Gimeno Sacristán (1998, 1999, 2000) sobre currículo com as de Paulo Freire a respeito da práxis, quando se evidencia a possibilidade de prática entrecruzada com a teoria, mostra um currículo construído, reconstruído, visitado e revisitado, ressignificado enquanto se constitui como prática por todo espaço de uma Comunidade Aprendente.

Tendo como horizonte de partida as teses propostas pela Ecologia Cosmocena, propomo-nos pensar um currículo que possibilite uma abertura de caminho para superação das múltiplas crises apontadas inicialmente neste texto. Para tanto pensamos um currículo alicerçado no princípio do pertencer, do ser e do cuidado.

$1^{\circ}$ CURRÍCULO COMO PERTENCIMENTO: para pensar em um currículo como princípio de pertença, recorremos à metáfora destacada por Pacheco (2004) como possibilidade de refletirmos sobre a inviabilidade de existência do sentimento de pertença na estruturação atual de 
nossa escola, onde todos são enquadrados em um mesmo sistema, em uma mesma categorização de disciplinas e avaliações, e distanciados de suas histórias, culturas e sentimentos.

As avezinhas aprendizes eram todas diferentes umas das outras. [...] Mas o manual de canto era igual para todos, o manual de vôo [sic] era igual para todos. Ensinava-se o piar discreto e em coro. Praticava-se o vôo [sic] curto, de ramo para ramo. Periodicamente, os mochos submetiam o receoso bando de aprendizes ao estranho cerimonial dos testes. As provas eram iguais para todos, num tempo igual para todos, com todos os pássaros aprendizes fechados no mesmo espaço. (PACHECO, 2004, p. 17-20).

Neste estranho cerimonial, estão inseridos todos e todas independentemente de suas subjetividades. Um currículo que deseja romper com esta formatação está atento a cada história que compõe a escola. O que se propõe com esta história é a reflexão sobre o currículo como possibilidade para além das disciplinas, para além dos manuais e rituais da escola tradicional. Assim, como nos desafia o autor, é preciso se arriscar como "[...] um pequeno grupo de gaivotas dissidentes, que, ao mergulhar na caverna profunda, encontra um tesouro. Esse tesouro trás, para além da caverna, possibilidades inter e transdisciplinares [...]" (PACHECO, 2004, p. 18), capazes de romper o paradigma tradicional, abalar as paredes de nossas escolas, e romper com nossa miopia dos saberes disciplinares. Nesse sentido, o filosofo Edgar Morin (2007, p. 30) chama a reflexão da transdisciplinaridade e que esta teria condições de quebrar as fronteiras rígidas entre as disciplinas, promovendo uma "religação dos saberes".

A realidade é complexa, distinta, permeada por múltiplos conflitos políticos, culturais, sociais; mas, um olhar de pertença é aquele que preza pelas pessoas que estão na escola e que a esta se sentem pertencentes. Não desejamos, nem faremos coro junto aos que apenas criticam a escola, os educadores e as educadoras, os educandos e suas múltiplas e distintas realidades histórico-temporal, mas desejamos provocar um pensar sobre a escola que temos seus silêncios curriculares, suas angústias heideggerianas, seus porões e suas nuances, considerando que "[...] somos profundamente enraizados em nossos universos culturais que ao mesmo tempo nos abrem e nos fecham as portas de outros possíveis conhecimentos" (MOURÃO, 2005, p. 252). Este sentido de pertença representa uma porta aberta para uma horizontalização de saberes e vivencias.

$2^{\circ}$ CURRÍCULO COMO MODO DE SER: pensar um currículo enquanto modo de ser - estar no e com o mundo; pensando que, ao sermos lançados no mundo, somos também lançados a vivência com o outro, a sentir o outro, ao 
conhecer-se e reconhecer-se no outro; afinal, é no acolhimento do outro, com quem coexistimos no mundo, que nos apropriamos do falar e do escutar, uma vez que pela linguagem nos constituímos como seres da linguagem. Este "da" linguagem traz consigo implicações que conduzem a um genuíno acolhimento do outro em sua essencialidade.

$\mathrm{O}$ acolhimento do ser pontuado por Martin Heidegger contribui, de maneira singular, para superação da compreensão metafísica do ser apenas como racional; contudo, permite atingirmos um entendimento acerca de um ser de linguagem. Acolher pode representar para o currículo uma mudança necessária embasada em um currículo de superação das dicotomias, das divisões das pessoas, das anulações do outro com quem convivemos; por esta razão, apontamos para o horizonte apresentado por Sato (2012, p. 2):

Há mais de mil anos falamos em matemática, geometria ou física, e não é verdade que tenhamos o sucesso dessas áreas nas escolas. A língua portuguesa, por exemplo, dispõe de uma enorme carga horária em relação às demais disciplinas, mas nem por isso as pessoas falam ou escrevem com gramática respeitável [...]. Existe um mosaico de tecido global na tessitura coletiva de pontos e nós, franjas e desenhos que conferem ligações entre pontos e linhas. Teremos de cuidar da escola - e basicamente da educação como um todo - se quisermos alcançar as mudanças desejadas. $\mathrm{E}$, para isso, os pequenos pontos que a constituem devem trabalhar conjuntamente. Não há um ou outro culpado, nem uma ou outra área que seja bem-sucedida. O tecido educativo é o conjunto desses erros e acertos.

Nesta tessitura coletiva de pontos e nos que o currículo Cosmoceno apresenta-nos oito possibilidades de aprendizagem, quais sejam: aprendizagem humanística relacional - o reconhecimento das outridades; aprendizagem como processo de valorização da vida - desenvolvimento integral dos processos cognitivos, afetivos, espirituais, estéticos e biológicos; aprendizagem enquanto hermenêutica dos saberes não reconhecidos - valorização da linguagem na abertura da compreensão de vivências epistemológicas e ontológicas; aprendizagem do cuidado - condição primeira de humanidade; aprendizagem com as diferenças - reconhecimento das pluralidades; aprendizagem transcendental - valorização da dimensão espiritual diante de nossa incompletude, como busca de sentido ontológico; aprendizagem do ambiente inteiro - superação da antiga separação da humanidade de todo o cosmos. Estas oito possibilidades representam a essencialidade do existir do ser ancorado na sua convivência com o outro através da linguagem.

Por certo pensar este currículo exige um desprender-se das estagnações e comodismos, mas representa também 
estabelecermos possíveis conexões com o outro, uma vez que neste horizonte coletivo há inúmeras possibilidades deconjuntamente superarmos esta educação que nos desumaniza, deseduca e nos distancia do outro, que nos cega a visão e nos ensurdece diante das injustiças e exclusões, que nos paralisa e nos dessensibiliza o olhar a dor do outro ou nossas próprias dores.

$3^{\circ}$ CURRÍCULO COMO CUIDADO: pensar nas teses da Pedagogia Cosmocena, cunhada por Pereira (2016) como sustentação para um Currículo que possa representar uma possibilidade para outra educação possível, no dizer de Freire e Shor (2006, p. 45), "uma educação que liberte, que não adapte, domestique ou subjugue", pensando em um cuidado como definição essencial do próprio existir do ser, como é abordado por Heidegger em Ser e Tempo. O sentido de cuidado está presente na essencial do existir humano, uma vez que sem a presença do cuidado a vida esvazia-se. Um currículo como cuidado aponta na direção da manutenção da vida e abre caminhos de respeito e convivialidade com todas as formas de vida que conosco coabitam esta Casa-Comum. Uma educação para com e pelo cuidado preza por todas as esferas da existência, apontando para educação como porta de acesso ao respeito cuidadoso que não exclui, oprime ou desconsidera o outro em seu próprio sentido de existir.

O cuidado é o oposto do descuido. Cuidado valoriza, solidariza, respeita, zela. Então, diante do cenário de descuido que vivemos, exige-nos uma delicadeza que cuida do outro, que se mantém atento às mudanças, e que, sobretudo, não seja um cuidado neutralizado, amordaçado, mas um cuidado atuante que reivindica uma ação, um movimento.

Pensar a educação, a escola, o currículo nestes tempos vividos, nestes tempos de incertezas tantas, de direitos encolhidos, de uma degradação da escola, do currículo, da descaracterização da subjetividade em nome de uma Base Nacional Comum que tenta cegar a criatividade e individualidade de cada região, por assim dizer, é uma tarefa que exige um olhar aberto e amplo, um reaprender a ver o mundo. Para tanto, o que pensamos como possiblidade para formação dos educadores deste tempo é a aposta em uma formação que promova o envolvimento de toda Comunidade que convive e compartilha com a escola os momentos vividos, as experiências, de forma a estreitar os laços de pertença entre "comunidade - escola - educador".

Qual espaço de cuidado a escola possibilita? Onde encontramos nela espaço para gratidão? Qual tempo de desacelerar temos em nossas instituições escolares? Quais as relações que aprendemos a estabelecer como os seres vivos que conosco coabitam esta casa-comum na escola?

Somente um trabalho coletivo e ciente das múltiplas realidades que compõem os contextos onde os educadores se encontram poderá apresentar algumas possíveis aberturas de respostas a estas e outras tantas questões que 
encontramos em nossas escolas. Concordamos com o mestre Paulo Freire, o qual defendeu que a "Educação não transforma o mundo. Educação muda pessoas. Pessoas transformam o mundo". estas pessoas são, por excelência, o educador que coletivamente busca aperfeiçoar-se e abrir-se para o diálogo com todos os contextos coletivos, individuais, com grupos de educandos, com coletivos comunitários, para que, unindo-se, naveguem para paragens que permitam outra educação possível.

Que educação buscamos? Aquela que nos movimente em direção à mudança, que nos conecte com a realidade de nosso país, uma educação crítica que não se feche a mera repetição de norte a sul dos mesmos conteúdos? Das mesmas repetições? Ou podemos, em um esforço coletivo, manifestar que é necessário o respeito à continentalidade do Brasil, à beleza de termos garantidos a dignidade e os direitos de todos e todas.

\subsection{A dignidade da pessoa humana a partir da perspectiva da Pedagogia Cosmocena}

A Constituição Federal de 1988 erigiu a dignidade da pessoa humana como princípio fundamental, ordenador e orientador de todo o sistema jurídico e político brasileiro. Estabelece ela, em seu primeiro artigo, que: "Art. $1^{\circ}$ A República Federativa do Brasil, formada pela união indissolúvel dos Estados e Municípios e do Distrito Federal, constitui-se em Estado Democrático de Direito e tem como fundamentos: [...] III - a dignidade da pessoa humana; [...]" (BRASIL, 1988).

A inserção da dignidade da pessoa humana nas Constituições modernas e contemporâneas, como um princípio jurídico, e não somente um valor, tem uma razão de ser. Barroso (2013, p. 18) afirma que a juridicização da dignidade da pessoa humana veio após a Segunda Guerra Mundial, quando, "[...] na reconstrução de um mundo moralmente devastado pelo totalitarismo e pelo genocídio, a dignidade humana foi incorporada ao discurso político dos vitoriosos como uma das bases para uma longamente aguardada era de paz, democracia e proteção dos direitos humanos"

Mas o fato é que ainda hoje não há consenso acerca do que seja a dignidade propriamente dita, sendo comum sua utilização, no âmbito jurídico brasileiro como "mero reforço argumentativo de algum outro fundamento ou como ornamento retórico" (BARROSO, 2013, p. 115). Portanto, é preciso estabelecer, como lugar de fala, nossa compreensão acerca do que seja dignidade, para que se possa pensá-la relacionada à Pedagogia Cosmocena.

No âmbito filosófico, a temática da dignidade foi sempre abordada, ainda que com perspectivas distintas. Dentre eles, merece destaque Immanuel Kant. Kant destacou-se ao estabelecer a dignidade como um valor intrínseco do ser humano, onde os indivíduos deveriam ser vistos como fins e nunca como meios, consoante um dos seus 
imperativos categóricos. Esse legado kantiano ainda hoje pode ser constatado, como no caso da Declaração Universal dos Direitos Humanos, de 1948, que expressa no seu primeiro artigo: "Todos os seres humanos nascem livres e iguais em dignidade e direitos. São dotados de razão e consciência e devem agir em relação uns aos outros com espírito de fraternidade" (ONU, 2009, p. 2). Para ele, a ideia de dignidade está associada à humanidade enquanto capaz de moralidade. Logo, Kant, restringe a dignidade aos seres humanos porque é uma espécie de valor da humanidade, consubstanciada na razão que permite o agir moral, elemento diferenciador dos demais seres.

Kant ainda defende que a dignidade do ser humano tem seu fundamento no fato do ser humano ter sido criado livre, independentemente de crença ou fé, o que permitiu uma compreensão secular acerca da dignidade humana. Ademais, daí deriva a concepção de autonomia, que para muitos é sinônimo de dignidade; neste viés kantiano, eis que significa que o ser humano é o senhor de si mesmo, o qual decide conforme seu arbítrio. Dessa forma, para uma síntese, a dignidade kantiana se funda na racionalidade e está centrada na autonomia da pessoa. E, é justamente em Kant que se sustenta parte considerável da doutrina dos direitos humanos (BARROSO, 2013).

Ora, ao estabelecer que o ser humano deve ser tratado com dignidade por ser um fim em si mesmo, temos que a dignidade humana pode ser compreendida como respeito, como aliás, já defendeu Joel Feinberg no sentido de que "[...] respeitar a dignidade das pessoas nada mais é que respeitar as pessoas, e respeitamos as pessoas exatamente da mesma forma que respeitamos a lei” (ROSEN, 2015, p. 27). O autor ainda explicita que "[...] respeito pelas pessoas pode significar, simplesmente, respeito pelos seus direitos, de maneira que um não pode existir sem o outro; e a chamada dignidade humana talvez seja simplesmente a capacidade reconhecível de fazer reivindicações" (ROSEN, 2015, p. 26).

Juridicamente, a compreensão de dignidade tem trilhado essa mesma percepção. Sarlet (2012, p. 52), a respeito disso, afirma que a dignidade da pessoa humana é

[...] a qualidade intrínseca e distintiva reconhecida em cada ser humano que o faz merecedor do mesmo respeito e consideração do Estado e da comunidade, implicando neste sentido, um complexo de direitos e deveres fundamentais que assegurem a pessoa tanto contra todo e qualquer ato de cunho degradante e desumano, como venham a lhe garantir as condições existenciais mínimas para uma vida saudável, além de propiciar e promover sua participação ativa e corresponsável nos destinos da própria existência e da vida em comunhão com os demais seres humanos, mediante o devido respeito aos demais seres que integram a rede da vida. ${ }^{2}$
2 O referido autor utiliza os parâmetros da Organização Mundial da Saúde para estabelecer que vida saudável se refere a um completo bem-estar físico, mental e social; afirmando ainda que esta diretriz mínima deve ser assegurada pelo Estado. 
Assim, para além da proibição de tratar o ser humano como meio, a ideia de dignidade humana impõe o dever de assistência por parte do Estado, inclusive, para que se efetive essa vida digna.

A grande discussão que se coloca contemporaneamente - e, inclusive, na seara jurídica - se dá ao alcance protetivo da ideia de dignidade. Em outras palavras, diante da crise ambiental (cosmocena), é suficiente uma perspectiva kantiana de dignidade da pessoa humana? Pensamos que não.

Pereira (2016) afirma que a crise civilizatória que se vive é resultado, dentre vários elementos, de um esgotamento do paradigma metafísico fundado sob o viés do antropocentrismo. Quer dizer, não há mais segurança em uma perspectiva de verdades absolutas onde o ser humano é o único senhor. Pelo contrário, este ser humano vive hoje uma síndrome do abandono, fruto de suas próprias escolhas.

Boff (2014) aponta um descuido e um descaso do ser humano consigo mesmo em múltiplas dimensões da vida, os quais vão desde a falta de cuidado na infância, passando pela sobrevivência material, até o desprezo pela Terra. Há, assim, uma ausência aguda de conexão conosco mesmos e com as outridades com as quais convivemos.

Nesse sentido, a ideia de dignidade da pessoa humana, insculpida na Constituição Federal, ainda que possa ser interpretada de forma mitigada ${ }^{3}$, ou alargada, se revela um instrumento insuficiente para lidar com esta crise ética entranhada no mundo. Isto porque, mesmo nessa perspectiva alargada, ainda é o ser humano o centro, a referência, a prioridade, enfim, e a relação harmônica com os demais seres tem o único propósito de garantir uma vida humana digna.

Assim, acredita-se que é urgente a necessidade de uma releitura do princípio constitucional, sob uma perspectiva proposta pela Ecologia Cosmocena, isto é, o princípio da dignidade precisa ser ressignificado a partir de uma compreensão do mundo que se habita para que os sentidos da existência humana sejam renovados em um olhar compassivo pelo outro. E, a Ecologia Cosmocena vem ao encontro desta proposta porque, surgindo da crise que se estabelece em uma diversidade de dimensões, propõe exatamente essa redefinição do espaço humano no universo, ou seja, reivindica o ser no tempo do cuidado, "[...] o zelo com o outro humano, com os não humanos, com os elementos da natureza e a construção de sociedades sustentáveis" (PEREIRA, 2016, p. 14).

Propõe-se repensar o lugar que o ser humano vem ocupando em uma perspectiva mais solidária em relação com o Outro, até porque a construção de um mundo sustentável surgirá do conceito com esta outridade, uma vez que a transcendência da racionalidade ambiental se dará "[...] pela fecundidade das relações com o Outro, pela produtividade da complexidade ambiental, pelo encontro de
3 Acerca deste antropocentrismo alargado, Canotilho afirma que: "Se tem a ideia de que, mesmo centrando as discussões a respeito de ambiente na figura do ser humano, propugna por novas visões do bem ambiental. Assim, centra a preservação ambiental na garantia da dignidade do próprio ser humano, renegando uma estrita visão econômica do ambiente. O "alargamento" dessa visão antropocêntrica reside justamente em considerações que imprimem ideias de autonomia do ambiente como requisito para a garantia de sobrevivência da própria espécie humana. Aqui, o ambiente não é visto como passaporte à acumulação de riquezas, sendo compreendido como elementar à vida humana digna. [...] essa nova percepção do meio ambiente fundamenta-se no interesse público, na integridade e na estabilidade ecológica da natureza, e não na utilidade direta dos elementos do meio ambiente para o homem" (LEITE, 2012, p. 163, grifos nossos). 
interesses antagônicos e pelo diálogo dos saberes" (LEFF, 2012, p. 120). É a ressignificação do mundo diante da crise instaurada e das exigências daí advindas, de onde se inserem a sustentabilidade, democracia e justiça social.

Aí está a necessidade premente de redimensionar o princípio da dignidade da pessoa humana para, em uma perspectiva cosmocena, um princípio da dignidade ambiental, reconhecendo um valor intrínseco a toda forma de vida no planeta.

Não restam dúvidas de que o Direito ainda é muito marcado pela razão cartesiana, e que reflexões de uma perspectiva biocêntrica ${ }^{4}$ para o princípio da dignidade ainda são muito modestas, o que deve nos mover a pensar juntos uma nova dignidade. Uma dignidade ambiental em que, como afirma Jonas (2005), se reconheça que existe algo de transcendente e espiritual na base de toda e qualquer vida, e, portanto, há um valor intrínseco a ser reconhecido à própria existência como tal.

Nesse sentido, por toda a crise instaurada, uma vez que "o homem tem de tomar cuidado para se proteger da [sua] tirania" (NUSSBAUM, 2017)5; e, estando a dignidade intrinsecamente relacionada a toda forma de vida, há que se reconhecer aqui a importância de uma pedagogia sob a perspectiva cosmocena, que propiciará o espaço adequado, formal ou não formal, para essa ressignificação da dignidade ambiental. Uma pedagogia que nos convida a, nas relações com as outridades, sermos constantes aprendentes da valorização da vida em todas as suas formas. Em apertada síntese, a Pedagogia Cosmocena nos convida à dignidade ambiental que se concretiza no respeito e no cuidado com o outro.

Portanto, não há mais espaço para se pensar no ser humano como senhor da razão e dos sentidos, como centro do mundo. A visão antropocêntrica, aqui especialmente marcada no Direito, é incompatível com a tradição democrática instaurada a partir de 1988 no Brasil, que agregou a dimensão ambiental aos direitos fundamentais - fundados no princípio da dignidade - e assim ambientalizou todo o sistema jurídico.

Justamente esta ambientalização do sistema impõe a produção de um novo sentido ao princípio da dignidade da pessoa humana para que - a partir de uma racionalidade ambiental, de cuidado, respeito e tolerância - o ressignifique como o princípio da dignidade ambiental, reconhecendo os plúrimos e diversos olhares que habitam o mundo, estabelecendo novas relações com esses outros.

Para tanto, a perspectiva cosmocena se apresenta como aquela que pode proporcionar o diálogo entre múltiplos saberes, pois é a partir do questionamento e da problematização da realidade, sob um olhar compassivo e solidário, que se promove um processo permanente de reflexão para o agir transformador de paradigmas consolidados que desconsideram a relação de dignidade intrínseca em ser o outro e ser com o outro.
4 O biocentrismo é uma corrente de orientação do pensamento jurídico que conectada à ética ambiental atribui importância a todos os seres. Surgiu na década de 1970, como contraponto ao antropocentrismo, a partir da Ecologia Profunda desenvolvida pelo filósofo Arne Naess (STOPPA; VIOTTO, 2014). Assim, enquanto no antropocentrismo se defende a responsabilidade do ser humano para com a natureza, no biocentrismo os deveres se apresentam diante da natureza.

5 Capítulo 1, segundo parágrafo. 


\section{Considerações finais}

Este texto propõe-se a pensar junto com cada leitor acerca do currículo, da escola, dos educadores e educadoras. Porém uma reflexão antecede este pensar, qual seja: Que espaços encontramos para uma escola que nos apaixone pela escolha de educar e educar-se? Que escolas temos, desejamos e sonhamos para que os educadores e educandos possam a elas sentirem-se pertencentes? Que escolha tem o educador, em nossas instituições para fortalecer sua identidade educadora?

São muitas as perguntas, as respostas não tantas, ou melhor, não as temos, mas "[...] notei que descobrir novos lados de uma palavra era o mesmo que descobrir novos lados de Ser" (BARROS, 2010. p. 280); por isso, escolhemos olhar o cenário de partida deste texto, como possibilidade, como oportunidade de "repensar" a educação sob a luz do encantamento, da escolha de vida por ser educador, mas uma escolha não calada, obediente, mas que movimenta, que desassossega, que sente a vida e aperfeiçoa-se tendo em vista a coletividade da educação.

A Ecologia Cosmocena como base para Pedagogia Cosmocena representa uma possibilidade de interligar a teoria à pratica. Espera-se, que esta interligação aconteça de maneira tão intensa que não seja mais possível dividir a teoria da prática, onde a prática seja a teoria e a teoria a prática da vida daquele que considera primordial que a educação coloque-se a caminho de cuidar, mediar saberes, partilhar gratidão, como uma Comunidade Aprendente que convive, coparticipa, através de suas escolhas da manutenção da vida em suas múltiplas formas de ser-com-e-no-mundo.

\section{Referências}

BARROS, Manuel de. Caderno de Apontamentos, Concerto a Céu Aberto Para Solos de Ave. In: BARROS, M. de. Poesia completa. São Paulo: Leya, 2010. p. 280.

BARROSO, Luís Roberto. A dignidade da pessoa humana no Direito Constitucional contemporâneo: A construção de um conceito jurídico à luz da jurisprudência mundial. Belo Horizonte: Editora Fórum, 2013.

BOFF, Leonardo. As quatro ecologias: ambiental, política e social, mental e integral. Rio de Janeiro: Mar de Ideias; Animus anima, 2012.

BOFF, Leonardo. Saber Cuidar. Petrópolis: Vozes, 2014.

FREIRE, Paulo; SHOR, Ira. Medo e ousadia: o cotidiano do professor. 11. ed. Rio de Janeiro: Paz e Terra, 2006.

GESSER, Verônica; RANGHETTI, Diva S. Currículo escolar: das concepções histórico-epistemológicas a sua 
materialização na prática dos contextos escolares. Curitiba: CRV, 2011.

BRASIL. Constituição (1988). Constituição da República Federativa do Brasil. Brasília, DF: Senado, 1988.

GIMENO SACRISTÁN, José. Aproximação ao conceito de currículo. In: GIMENO SACRISTÁN, José. O currículo: uma reflexão sobre a prática. Porto Alegre: ArtMed, 1998. p. $13-87$.

GIMENO SACRISTÁN, José. A cultura para os sujeitos ou os sujeitos para a cultura? O mapa mutante dos conteúdos na escolaridade. In: GIMENO SACRISTÁN, José. Poderes instáveis em educação. Porto Alegre: ArtMed, 1999. p. 147-206.

GIMENO SACRISTÁN, José. O currículo: os conteúdos do ensino ou uma análise prática. In: GIMENO SACRISTÁN, José; PÉREZ GÓMEZ, Angel Ignacio. Compreender e transformar o ensino. 4. ed. Porto Alegre: ArtMed, 2000. p. 119-148.

HAMILTON, David. Sobre as origens dos termos classe e curriculum. Teoria \& Educação, n. 6, p. 33-51, 1992.

IVAR DO SUL, Juliana Assunção. Uma nova época na história geológica da Terra? Ciência hoje, v. 333, p. 56-57, 2016.

JONAS, Hans. O princípio da vida: fundamentos para uma biologia filosófica. Petrópolis: Editora Vozes, 2005.

LEFF, Henrique. Racionalidade ambiental: a reapropriação social da natureza. Rio de Janeiro: Civilização Brasileira, 2006.

LEFF, Enrique. Aventuras da Epistemologia Ambiental: da articulação das ciências ao diálogo dos saberes. São Paulo: Cortez, 2012.

LEITE, José Rubens Morato. Sociedade de Risco e Estado. In: CANOTILHO, José Joaquim Gomes; LEITE, José Rubens Morato (Org.). Direito Constitucional Ambiental Brasileiro. São Paulo: Saraiva, 2012.

LOUREIRO, Carlos Frederico B. Trajetória e fundamentos da educação ambiental. São Paulo: Cortez, 2004 .

LOVELOCK, James. Gaia: alerta final. Rio de Janeiro: Intrínseca, 2010.

MOREIRA, Antonio Flávio; CANDAU, Flavio Barbosa; MOREIRA, Vera Maria. Currículo, conhecimento e cultura. 
In: BEAUCHAMP, Jeanete; PAGEL, Sandra Denise; NASCIMENTO, Aricélia Ribeiro do (Org.). Indagações sobre o currículo. Brasília: Ministério da Educação/Secretaria de Educação Básica, 2007. p. 17-48.

MOREIRA, Antonio Flávio; MACEDO, Elizabeth (Org.). Currículo, práticas pedagógicas e identidades. Porto: Porto Editora, 2002.

MORIN, Edgar. Os sete saberes necessários à educação do futuro. 12. ed. São Paulo: Cortez, 2007.

MOURÃO, Laís Sá. Pertencimento. SÁ, Laís Mourão. Pertencimento. In: FERRARO JR., Luís Antônio (Org.). Encontros e caminhos: formação de educadoras(es) ambientais e coletivos educadores. Brasília: MMA, Diretoria de Educação Ambiental, 2005. p. 245-255.

NUSSBAUM, Martha. Sem fins lucrativos: por que a democracia precisa das humanidades. São Paulo: WF Martins Fontes, 2017. [Kindle Edition].

ORGANIZAÇÃO DAS NAÇÕES UNIDAS. Declaração Universal dos Direitos Humanos. Rio de Janeiro: UNIC, ago. 2009.

PEREIRA, Vilmar Alves. Ecologia Cosmocena: a redefinição do espaço humano no cosmos. Juiz de Fora: Garzia edizioni, 2016.

PACHECO, José. Para Alice, com amor. Rio de Janeiro: Vozes, 2004.

ROSEN, Michael. Dignidade. São Leopoldo: Editora Unisinos, 2015.

SARLET, Ingo W. Dignidade da Pessoa Humana e Direitos Fundamentais na Constituição Federal de 1988. Porto Alegre: Livraria do Advogado, 2012.

SATO, Michèle. É preciso ousar mudanças. Pátio - revista pedagógica, n. 64, p. 18-21, nov. 2012.

STOPPA, Tatiana; VIOTTO, Thaís Boonem. Antropocentrismo x Biocentrismo: um embate importante. Revista Brasileira de Direito Animal, Salvador, v. 9, n. 17, 2014. Disponível em: https://portalseer.ufba.br/index. php/RBDA/issue/view/1031/showToc. Acesso em: 1 mar. 2018.

VALE, Petterson Mollina; CAIXETA, Daniel Andrade. "Fronteiras planetárias" e limites ao crescimento: algumas implicações de política econômica, v. 22, july 2014. Disponível em: https://ideas.repec.org/a/rib/revibe/rev22_05.html. Acesso em: 4 mar. 2018. 
WILSON, Edward Osborne. A criação: como salvar a vida na terra. Tradução de Isa Mara Lando. São Paulo: Companhia da Letras, 2008.

ZALASIEWICZ, Jan. Antropoceno: cientistas proclamam que estamos no nascimento de uma nova era geológica. Eco Debate, 7 jun. 2011. Disponível em: https://www. ecodebate.com.br/2011/06/07/antropoceno-cientistas-proclamam-que-estamos-no-nascimento-de-uma-nova-era-geologica/. Acesso em: 4 mar. 2018.

ZOHAR, Danah; MARSHALL, Ian. QS: inteligência espiritual. Tradução de Ruy Jungmann. Rio de Janeiro: Viva Livros, 2012.

Recebido em: 11/10/2019 Aprovado em: 08/11/2019 Publicado em: 20/12/2019 